\title{
Evaluation of the quality of filter washing water and decanter sludge after sequential treatment by drainage bed, dissolved air flotation, and filtration
}

\author{
Nilton Fernandes de Oliveira ${ }^{1}$, André Luiz de Oliveira ${ }^{2}$ \\ ${ }^{1}$ Environmental Engineer, Master in Civil Engineering by the Graduate Program in Civil Engineering, Federal University of Uberlândia, Minas Gerais, Brazil. \\ ${ }^{2}$ Civil Engineer, Ph.D. in Hydraulic Engineering and Sanitation, Professor of the Post-Graduation Program in Civil Engineering, Uberlândia Federal University, \\ Minas Gerais, Brazil.
}

Correspondence Author: Nilton Fernandes de Oliveira, Environmental Engineer, master's in civil engineering by the Graduate Program in Civil Engineering of the Federal University of Uberlândia, Minas Gerais, Brazil.

E-mail: niltonea@ outlook.com

Received date: 18 March 2019, Accepted date: 5 May, Online date: 25 May 2019

Copyright: (C) 2019 Nilton Fernandes de Oliveira et al., This is an open-access article distributed under the terms of the Creative Commons Attribution License, which permits unrestricted use, distribution, and reproduction in any medium, provided the original author and source are credited.

\begin{abstract}
In the present study, following the treatment in the sequential drainage bed (LD), dissolved air flotation (FAD), and filtration, all being on bench scale, the evaluation of the quality of the sludge decanter and filter washing water was carried out, at the Bom Jardim Water Treatment Station, located in the city of Uberlândia-MG. Subsequently, effluents from drainage beds, composed of three types of different geotextile blankets ( RT-21, RT-26, and RT-31) were evaluated, followed by the analysis of three types of sand grading used in the present work. Upon being passed through the drainage bed, the drained effluents were directed to pass through the flotation unit by dissolved air, and subsequently, through the filtration units. The analysis was carried in two stages: stage I, and stage II. In stage I, the experiment was carried out in the absence of the coagulating agent or auxiliaries in coagulation/flocculation of the flotation. The samples, after passing through the system, were evaluated for physical parameters such as (i) pH, (ii) turbidity, (iii) true color, and (iv) apparent color, in addition to, chemical parameters, thereby determining the remaining concentrations of aluminum and iron. On the other hand, stage II involves the tests similar to those carried out in stage $I$, but in the presence of three different concentration $(5,10$, and $15 \mathrm{mg} / \mathrm{L}$ ) of the coagulant (aluminum sulfate), mainly used in coagulation/flocculation. Upon analyzing the results obtained from both stage I and II, one can deduce that test performed with the RT-26 blanket at the exit of Filter 01, in stage $I$, showed better performance, with the reduction being $91.8 \%, 41.4 \%$, and $97.6 \%$, of the apparent color, true color, and turbidity, respectively. However, in stage II, the best performance was observed, with the drainage of the RT-26 blanket at the outlet of Filter 02, upon being subjected to a dose of $15 \mathrm{mg} / \mathrm{L} \mathrm{of}$ aluminum sulfate. The experiment demonstrated a reduction of $96.4 \%$ of the apparent color, $86.2 \%$ of the true color, and $99.6 \%$ of the turbidity. Therefore, the results establish the efficiency of the system in the removal of solids present in the filter washing water and the sedimentation sludge from the ETA studied. Thus, the study affirms that this system can be a potential alternative of the sludge discharge as well as can become an option of a new treated water supply line.
\end{abstract}

Keywords: water treatment plant, drainage Bed, geotextiles, dissolved air flotation

\section{INTRODUCTION}

Water plays a crucial role in every creatures life. Essentially, it is one of the most important elements in the life of every creature on the earth, as it drives the overall existence of all the individuals every day. Among various countries, Brazil has many sources of fresh water. But the availability of fresh water on the planet is declining day by day due to pollution and contamination of both surface and groundwater. Various wastewater treatment plants have been set-up for treating polluted water. However, the waste or the sludge obtained from these treatment plant, which is either disposed of by dumping in the ocean or by applying it to land as a fertilizer or by using the landfill method, are found to become one of the reasons for increasing the water pollution. Therefore, there is an urgent need to understand the importance of managing the waste generated by the Water Treatment Stations (ETS), in addition to, the various actions taken for the preservation and maintenance of water bodies (Barroso, 2007), because the lack of environmental planning and control can lead to scarcity.Upon closely analyzing the by-products or the residues generated 
Citation: Nilton Fernandes de Oliveira, et al., Evaluation of the quality of filter washing water and decanter sludge after sequential treatment by drainage bed, dissolved air flotation, and filtration. Australian Journal of Basic and Applied Sciences, 13(5): 35-42. DOI: 10.22587/ajbas.2019.13.5.4

by the ETA, one can observe that it is mainly composed of branches, leaves, trunks, sand, silt, clay, humic substance, and metal salts. Among these, the branches, leaves, trunks, etc. get eliminated in the grating phase. However, the coagulants added to the wastewater, in the coagulation process, becomes the main source of the metal salts in the residue. According to NBR 10004: 2004, the sludge produced in an ETA has been designated as solid waste, as it possesses high humidity, usually higher than $95 \%$ (Cordeiro et al., 2001). Further, the release of such waste in the natural environment has been prohibited. However, most of the water treatment systems still dispose of their waste in nearby water bodies.

On a similar note, the Federal Law 12,305 (2010) has mentioned that in the management of solid waste, necessary actions must be taken in the following order of priority: (i) non-generation, (ii) reduction, (iii) reuse, (iv) recycling, (v) solid waste treatment, and (vi) environmentally appropriate disposal of tailings. In other words, the analysis of the waste/residues produced by ETA, according to the priority scale, before discharging it into the waterways or disposing of in the landfills has become mandatory. Additionally, the possibilities regarding reuse of waste from a certain ETA, considered as tailings, must be verified. The above actions are necessary for reducing the numerous negative impacts such as (a) changes in aquatic biota, (b) soil contamination, (c) contamination of ground and surface water, (d) contamination of local flora and fauna, all being witnessed due to the release of ETA sludge into rivers and streams.

Principally, the sludge or the residues exist in two phases: (a) solid phase, and (b) liquid phase. Further, the liquid phase is sub-divided into four fractions: (i) free, (ii) flaky, (iii) capillary water, and ( iv) absorbed. The first fraction, i.e. the free water, mostly removed from the sludge in either of the three ways: (a) naturally, (b) by employing the process of Drainage Beds (LD), or (c) by another existing method, thereby leading to the procurement of a substantial amount of water. However, from the last several years, the drainage technique was mainly utilized for the removal of water from the sludge.

According to the literature study, Cordeiro (2001) was among one of the pioneers who used the drainage technique, in Brazil, for removing water from the sludge. Fundamentally, his proposal led to the replacement of the conventional drying bed structure, constituted of layers of rubble, coarse sand, and bricks, with a geotextile blanket. From then onwards, several studies and surveys, involving the use of drainage beds, was carried out, which in turn revealed that the modified drainage beds aided the process of dewatering sedimentation sludge, obtained from ETA, and thereby shows the potential of removing water from the sludge efficiently (Cordeiro, 2001; Achon\&Cordeiro, 2003; Fontana, 2004; Barroso, 2007; Santos, 2012).

In comparison to other water withdrawal systems, particularly the mechanical ones, these drainage beds have several advantages such as; these beds being natural systems requires a low cost for the application and maintenance. Consequently, the practicability or feasibility of such beds becomes more. In other words, the viability of these beds increases (Mott\&Romano, 1992). These benefits have promoted the real application of this technique for the dewatering of ETA sludge in some municipalities of Brazil, with a further manifestation of efficient results, being corroborated by Cordeiro et al. (2001), Achon\&Cordeiro (2003), and Fontana (2004). The main features of this type of system in terms of efficiency is the rapid drainage of free water, which makes it readily available, and the efficient reduction of impurities generally measured under the aspect of turbidity.

Further, the assumption that approximately $5 \%$ of waste gets generated on the gross production of water per day (Cordeiro et $a l ., 2001)$, necessitates the evolution of studies which can evaluate the reuse potential of the constituent water, thereby replacing the process of discharging sludge into water resources. However, use of only drainage bed residues does not fulfill the above requirements, as it does not have adequate characteristics for this purpose. Nevertheless, this can be achieved by the use of the combination of the physicochemical process of flotation by dissolved air and sand filtration for the post-treatment of the drainage, as both the technologies are well diffused, with their efficiencies being proven in the technical and scientific community.

The objective of this work was to evaluate the water quality of filter washing and decanter sludge from the Water Treatment Plant Bom Jardim - Uberlândia/MG, after sequential treatment by drainage bed (LD), dissolved air flotation (FAD) and filtration, All on bench scaleo.

\section{MATERIALS AND METHODS}

In order to evaluate the existence or not of significant differences in the removal values achieved in the treatments evaluated in this study, in relation to the parameters True color, apparent color, turbidity and $\mathrm{pH}$, during the different contact times Used the statistical method of comparing means of two samples and the analysis of the parameters in the laboratory were performed in triplicate.

Following the treatment in the sequential drainage bed (LD), dissolved air flotation (FAD), and filtration, all being on bench scale, the evaluation of the quality of the sludge decanter and filter washing water was carried out, in the present study, at the Bom Jardim Water Treatment Station, in the city of Uberlândia, MG. Subsequently, three different LD, having similar characteristics but different geotextiles were utilized. Additionally, for carrying out the Jar test, the three jars were filled with the effluent from an LD, followed by the arrangement of three filters with different particle sizes. Further details are provided, in the relevant item. Finally, the test was accomplished, by using the structure of the Sanitation Laboratory of the Faculty of Civil Engineering of the Federal University of Uberlândia.

With an aim to further confirm two crucial control parameters: sufficient drainage volume (later used in FAD and filtration) and solid application rate (TAS), a mixture of decanter sludge and filter wash water, was employed as the crude sample. The measurement of the SST in drainage beds (LD) was mainly expressed, in terms of the total kilograms of solids per square meter of bed (Kg ST.m-2). Notably, this measurement unit indicates that for a given TAS, higher is the concentration of solids in the sample to be treated, smaller is the required volume of the sample, whereas lower is the concentration of the solids, higher is the volume of the required sample. In the present study, the most suitable configurations of TAS with a value of $3.5 \mathrm{Kg} \mathrm{ST}$.m-2 was used, upon extracting it from the work of Santos (2012). Further, to corroborate this TAS value, the composition of the sludge 
sample, which includes both decanter sludge and filter wash water, was essential because it is the sludge sample which is being used from the decanter for the treatment, as decanter was very concentrated, and enough drainage volume would not be present, for treatment, in the FAD and filtration units. However, this "mixing" of the sludge samples changes significantly only the concentration of solids as the origin of the sludge remains the same, thereby retaining the same characteristics of the individual samples.

The investigation, in the current work, was carried out in two stages: (i) stage I, and (ii) stage II. However, preliminary tests were carried out, essentially for characterizing the sludge sample regarding its physical, chemical and biological parameters, in addition to, the evaluation of the drainage characteristics, which mainly involves the assessment of the water that passes from the sludge through the drainage bed.

In stage I, the test were performed with the pilot units, by maintaining the following parameters: (i) the fast mixing gradient (Gmr), (ii) fast mixing speed (Vmr), (iii) average velocity gradient (Gf), (iv) flotation velocity (Vf), (v) pressure (P) inside the pressurizing chamber, and (vi) the saturation time (Tsat). Further, no coagulating agents were added throughout the analysis. Moreover, the above procedure was based on the hypothesis that even in the absence of additional external coagulating agents, the reduction in turbidity in the FAD and the filters would occur efficiently. Notably, one should commemorate that in the drained water, a considerable concentration of metallic salts was present owing to its origin.

In stage II, all the tests carried out in stage I was repeated. However, in this stage, different concentrations of aluminum sulfate were introduced as a coagulant in the fast FAD mixture, with the concentrations being $5.0 \mathrm{mg} / \mathrm{L}, 10.0 \mathrm{mg} / \mathrm{L}$, and 15.0 $\mathrm{mg} / \mathrm{L}$. Further, the tests performed in this stage relies on the hypothesis that the turbidity reduction efficiency would increase significantly in the presence of coagulants in this stage, even though it got reduced in the absence of coagulants in stage I.

\section{RESULTS AND DISCUSSION}

\section{Characterization of Sludge}

The evaluations regarding the physical, chemical, and biological parameters of the mixture of the sludge from the decanter and the washing water, obtained from the ETA Bom Jardim filters, was carried out. Table 1 depicts the physical parameters and their respective values, along with the predicted reference values of CONAMA resolutions $\mathrm{n}^{\circ}$ 357, of March 17, 2005, and COPAM / CERH $n^{\circ}$ 01, of May 05, 2008. Similarly, Table 2 and 3 show the values of chemical and biological parameters, respectively.

Table 1: Table showing the physical parameters of the decanter sludge mixture with filter wash water.

\begin{tabular}{|c|c|c|c|c|}
\hline Physical Parameters & $\begin{array}{c}\text { Sludge decanter } \\
\text { /Water filter } \\
\text { washing }\end{array}$ & Units & $\begin{array}{c}\text { CONAMA } \\
\text { No. 357 (2005) }\end{array}$ & $\begin{array}{c}\text { COPAM/CERH } \\
\mathbf{N}^{\circ} \text { 01(2008) }\end{array}$ \\
\hline pH & 6,72 & ---- & 5 a 9 & 6 a 9 \\
\hline Turbidity & 6.666 & UNT & 100 & -- \\
\hline True Color & 30,0 & UC & 75 & -- \\
\hline SD & 347,0 & $\mathrm{~mL} / \mathrm{L}$ & -- & -- \\
\hline ST & 13.066 & $\mathrm{mg} / \mathrm{L}$ & $500^{*}$ & $100^{* *}$ \\
\hline
\end{tabular}

SD = Sólidos Sedimentáveis; ST = Total Solids; $(*)=$ Dissolved; $(* *)=$ Suspension

Table 2: Table presenting the chemical parameters of the decanter sludge mixture with the filter wash water.

\begin{tabular}{|c|c|c|c|c|}
\hline $\begin{array}{c}\text { Chemical } \\
\text { Parameters }\end{array}$ & $\begin{array}{c}\text { Sludge decanter } / \\
\text { Water filter } \\
\text { washing }\end{array}$ & Units & $\begin{array}{c}\text { CONAMA 430 } \\
\mathbf{( 2 0 1 1 )}\end{array}$ & $\begin{array}{c}\text { COPAM / CERH } \\
\mathbf{( 2 0 0 8 )}\end{array}$ \\
\hline BOD & 233,33 & $\mathrm{mg} / \mathrm{L}$ & 5 & 60 \\
\hline COD & 557,70 & $\mathrm{mg} / \mathrm{L}$ & -- & 180 \\
\hline Total Copper & 0,3 & $\mathrm{mg} / \mathrm{L}$ & 1,0 & 1,0 \\
\hline Total Iron & 246,40 & $\mathrm{mg} / \mathrm{L}$ & 15,0 & 1,0 \\
\hline Total Manganese & 25,16 & $\mathrm{mg} / \mathrm{L}$ & 1,0 & 1,0 \\
\hline Total Nickel & $<0,05$ & $\mathrm{mg} / \mathrm{L}$ & 2,0 & 5,0 \\
\hline Total Zinc & 0,40 & $\mathrm{mg} / \mathrm{L}$ & 5,0 & 0,1 \\
\hline Total Aluminum & 615,40 & $\mathrm{mg} / \mathrm{L}$ & 0,1 & 0,1 \\
\hline Total Lead & 0,07 & $\mathrm{mg} / \mathrm{L}$ & 0,5 & 0,5 \\
\hline Total Chrome & 0,56 & $\mathrm{mg} / \mathrm{L}$ & 0,1 & \\
\hline
\end{tabular}

Table 3: Table describing the biological parameters of the decanter sludge mixture with the filter wash water.

\begin{tabular}{|c|c|c|c|c|}
\hline $\begin{array}{c}\text { Biological } \\
\text { Parameters }\end{array}$ & $\begin{array}{c}\text { Sludge decanter / } \\
\text { Water filter } \\
\text { washing }\end{array}$ & unity & $\begin{array}{c}\text { CONAMA } \\
\mathbf{4 3 0}(\mathbf{2 0 1 1})\end{array}$ & $\begin{array}{c}\text { COPAM / CERH } \\
\text { (2008) }\end{array}$ \\
\hline Escherichia coli & 100 & NMP/100 mL & -- & -- \\
\hline Helminth eggs & $*$ Presence & ---- & -- & -- \\
\hline
\end{tabular}

* Presence of Hookworm Eggs and Balantidium coli cysts. 
Upon closely comparing the parameter values, shown in their respective tables, with the reference values affirmed by the federal and state laws, principally taking into consideration the laws 13,199 (1999) and 9,433 (1997), one can deduce that the residues analyzed, in the present study, cannot be discharged directly into water bodies, because the values are well above the reference values i.e. the values allowed by the law. Additionally, the direct discharge of sludge into water bodies is prohibited in Brazil, as its release in nature via any methods, will cause serious environmental damages as well as may lead to serious health issues in human beings and animals that depend on these hydric body. Therefore, the above comparison reinforces the importance of improving the waste treatment techniques, in order to keep an eye on the waste generated by ETAs, thereby following the law mentioned under Law no. 9,605, of February 12, 1998, included in Article 54, paragraph 2, item V, which states that the launching of this type of waste in the course of water, will be considered as an environmental crime.

On a similar note, the development and application of systems, like the one proposed in the present work, become of paramount importance. Moreover, several techniques have been used, in the management of this type of waste. Among them, one of the technique comprises the return method, which involves the return of the sludge generated from their own system. However, there are limits to the return of sludge mainly due to health security, because sometimes a situation might arise where the volume of sludge exceeds the maximum return allowed. Therefore, it draws attention to the importance of introducing an independent system as it is in the present case.

\section{Characterization of Drainage}

The physical characteristics of the drainge of the three drainage beds were characterized, with Table 4 showing the results of the analysis.

Table 4: Table illustrating the physical characteristics of the drainage of the three drainage beds.

\begin{tabular}{|c|c|c|c|}
\hline Mantas & Parameters & Results & Units \\
\hline \multirow{4}{*}{ RT-21 } & pH & 7,8 & --- \\
\cline { 2 - 4 } & Turbidity & 72 & UNT \\
\cline { 2 - 4 } & True Color & 42 & UC \\
\cline { 2 - 4 } & Apparent Color & 250 & UC \\
\hline \multirow{4}{*}{ TR-26 } & pH & 7,9 & --- \\
\cline { 2 - 4 } & Turbidity & 125 & UNT \\
\cline { 2 - 4 } & True Color & 29 & UC \\
\cline { 2 - 4 } & Apparent Color & 281 & UC \\
\hline \multirow{4}{*}{ RT-31 } & pH & 7,8 & --- \\
\cline { 2 - 4 } & Turbidity & 132 & UNT \\
\cline { 2 - 4 } & True Color & 49 & UC \\
\cline { 2 - 4 } & Apparent Color & 307 & UC \\
\hline
\end{tabular}

A significant reduction in the turbidity values of the three blankets was observed, with the reduction value being $99 \%, 98 \%$, and $98 \%$, respectively. The present study aims to evaluate the efficiency of drainage beds as compared to the values found in Table 1. The analysis proved that LDs were extremely efficient in reducing turbidity. However, one could not observe same for true color, whose values remained practically unchanged. The observation can be explicated, by clarifying the fact that during the passage of sludge water by LD, chemical precipitation did not occur, as this process took place earlier at the source of the sludge. Moreover, the demonstration of the existence of dissolved substances by the true color, with the sample being free of suspended particles, further validates the above explanation.

\section{Step I: Assays Without Addition of Coagulating Agent}

With the intention of analyzing the water quality of the FAD unit, the collection of the samples were carried out at the outlet of the jars (FAD), followed by the analysis of the physical parameters of the collected samples such as (i) apparent color, (ii) true color, (iii) turbidity, and (iv) $\mathrm{pH}$. The results of these analyses are being tabulated in Table 5. On the other hand, the physical parameters of the samples collected at the filter outputs were also analyzed, with the result being displayed in Table 6 . The parameters analyzed for the drainage, after passing through the FAD unit and Filter 01, showed variation. Upon comparing the three processes, a significant reduction was observed, in the values of apparent color and turbidity, which in turn indicates the great efficiency of the system. The observation also draws attention towards the major role played by the filter in the retention of impurities. Apart from this, one can also infer that this step is indispensable in the treatment sequence, although replicating realtime systems was not possible. Further, at both the outputs ( FAD output and the Filter 01 output), the values of true color were found to be constant, which suggests that the dissolved substances which confer color were not retained. The observation led to the conclusion that these substances were removed, by getting absorbed on the filter medium, because precipitation or retention of these substances would have resulted in variation in the values of true color.

Table 5: Table presents the parameters analyzed in the exits of the jugs-Manta RT-21.

\begin{tabular}{|l|l|}
\hline Parameters & JARROS 01, 02 e 03 \\
\hline Apparent Color (UC) & 77 \\
\hline Apparent Color (UC) & 17 \\
\hline Turbidez (UNT) & 33 \\
\hline
\end{tabular}


Citation: Nilton Fernandes de Oliveira, et al., Evaluation of the quality of filter washing water and decanter sludge after sequential treatment by drainage bed, dissolved air flotation, and filtration. Australian Journal of Basic and Applied Sciences, 13(5): 35-42. DOI: 10.22587/ajbas.2019.13.5.4

$\mathrm{pH}$ 7,6

Table 6: Table represent the parameters analyzed in the filter outputs-Manta RT-21.

\begin{tabular}{|c|c|c|c|}
\hline Parameters & Filter 01 & Filter 02 & Filter 03 \\
\hline Apparent Color (UC) & 24 & 24 & 26 \\
\hline True Color (UC) & 17 & 17 & 17 \\
\hline Turbidez (UNT) & 3 & 3 & 5 \\
\hline $\mathrm{pH}$ & 7,9 & 8,2 & 7,9 \\
\hline
\end{tabular}

Figure 1, 2, and 3 demonstrate the efficiency of Filters 01, 02, and 03 installed after the FAD unit submitted to the drains of the LDs, constituted by the blankets RT-21, RT-26, and RT-31.

Figure 1: The graph depicts the efficiency of turbidity removal, true color, and apparent color of the system composed of LD (blankets RT-21, RT-26, RT-31), FAD, and Filter 01.

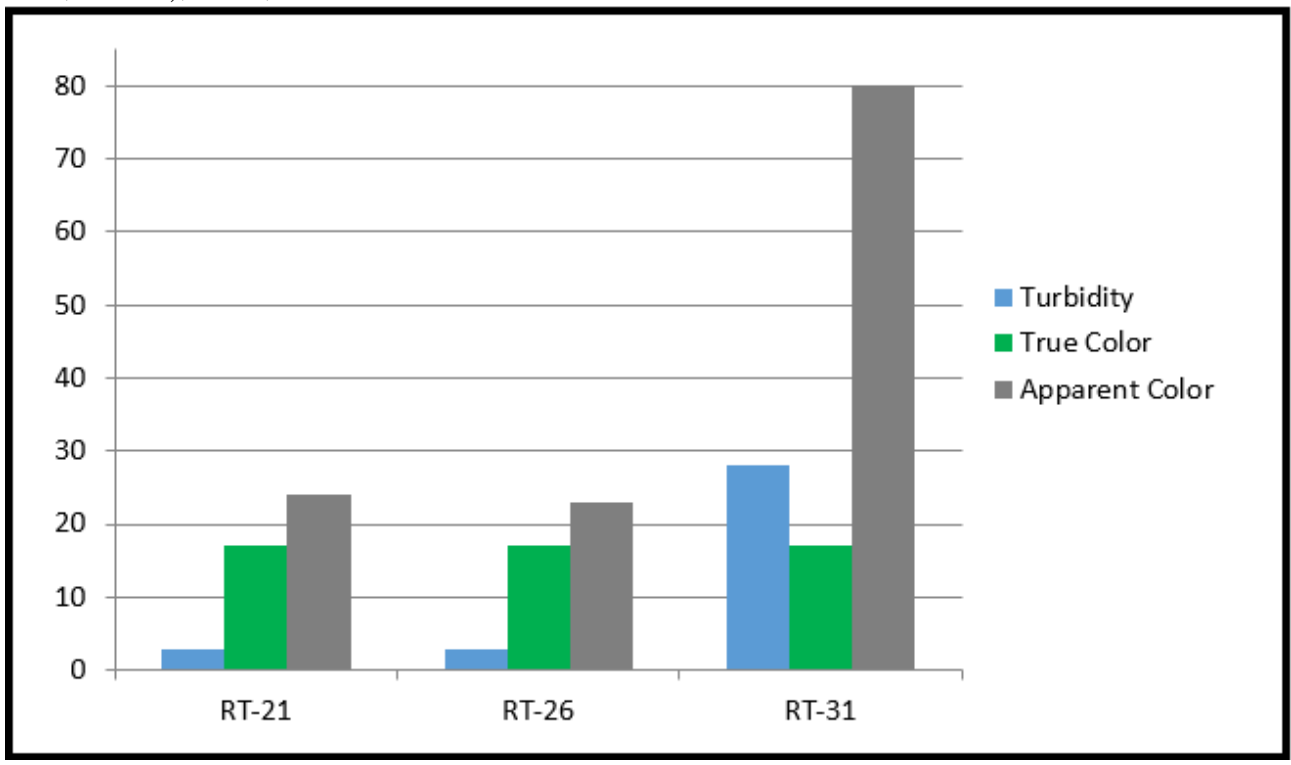

Figure 2: The graph portrays the efficiency of removal of turbidity, true color, and apparent color of the system composed of LD (blankets RT-21, RT-26, RT-31), FAD, and Filter 02.

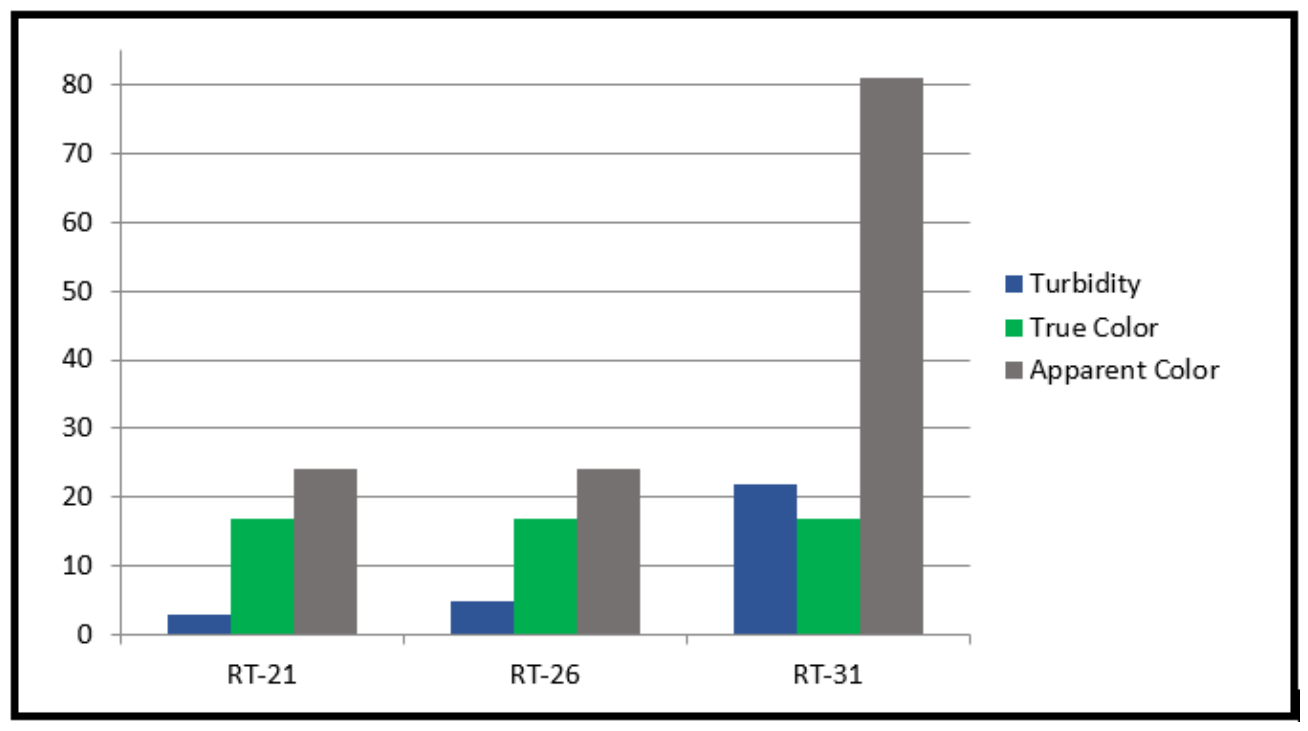


Figure 3: The graph illustrate the efficiency of turbidity removal, true color, and apparent color of the system composed of LD (blankets $R T-21, R T-26, R T-31$ ), FAD, and Filter 03.

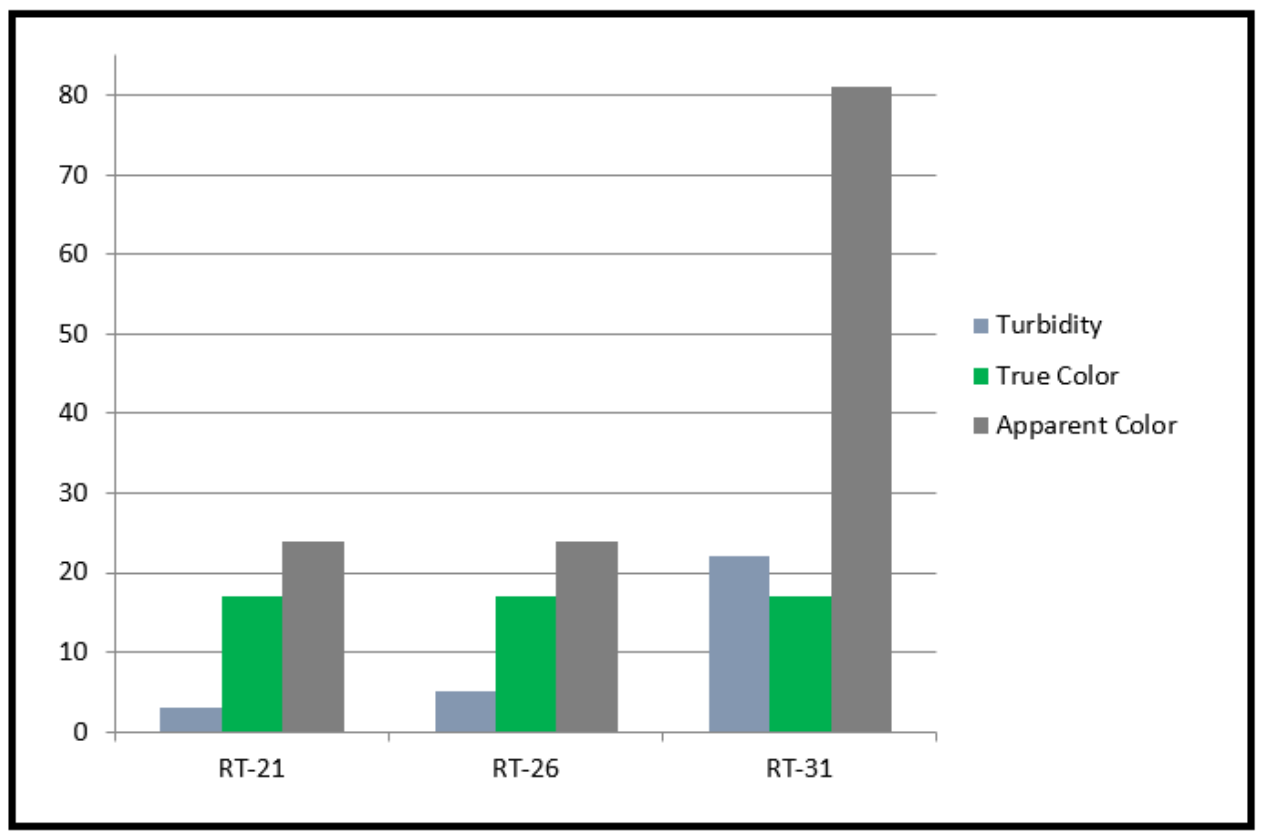

From figure 1, one can observe that throughout the system composed of LD-FAD-Filter 01, the resulting apparent color remained higher, with the removal of this parameter being $73.9 \%$, in the presence of the geotextile sheet RT-31 in the drainage system. However, when the geotextile sheet RT-31 was replaced, by either geotextile RT-21 or RT-26 in the drainage system, the removal of apparent color was found to be $90.4 \%$ and $91.8 \%$, respectively. On the other hand, in the case of all the three worked blankets (RT-21, RT-26, RT-31) used in the drainage system, the reduction in the turbidity was observed to be $89.6 \%$ (arithmetic mean).

In the system composed of LD-FAD-Filter 02, the turbidity removal efficiency for Manta RT-21, Manta RT-26, and Manta RT-31, was $90.4 \%, 91.4 \%$, and 73.6\%, respectively. Further, the removal efficiency of apparent color for Manta RT-21, Manta RT-26, and Manta RT-31, was $95.8 \%, 96.0 \%$, and $83.3 \%$, respectively. The results suggest that in the presence of the RT-21 and RT-26 blankets in the drainage system, better suspension retention was observed throughout the system, while the subsequent FAD and filtration units showed higher retention for turbidity and apparent color values.

The graphical representation of the results shown in figure 3, unveils that in the system composed of LD-FAD-Filter 03, submitted to the FAD unit, and drained from the RT-21, RT-26, and RT-31 blankets, the removal efficiency of the apparent color and turbidity was found to be $84.1 \%$ and $90.6 \%$, respectively. Further, upon comparing the values of apparent color and turbidity observed in this filtration unit (Filter 03), with the other filtration units used in the present study (Filters 01 and 02), less removal of suspended solids, passing from the FAD unit to the filters, was witnessed. Moreover, this observation can be attributed, to the presence of larger sand grains in the filter medium used in Filter 03, in comparison to other filters, with the size of the sand grains being $1.19 \mathrm{~mm}$ (measured by granulometry) in Filter 03.

The true color in all the tests carried out in this stage, both in the analyses of the samples collected (i) after the FAD unit, and (ii) after the filtration unit, was at 17 UC. Predominantly, the supply water of the city of Uberlândia was being categorized as class II, and according to the resolution CONAMA n ${ }^{\circ} 357 / 2005$ the maximum limit of true color for waters of class II should not exceed 75 UC. Since the value of true color, in the present study, is below the maximum limit, hence can be considered agreeable, which in turn further establishes that the system was highly efficient in removing the true colors.

Taking into consideration the $\mathrm{pH}$ values, in all the tests carried out in this stage, was found to vary from 7.6 to 8.5 , which according to Ministry of Health Ordinance No. 2,914/2011, falls within the recommended range (6.0 to 9.5). However, the slight variation was considered negligible, as did not alter the performance of the water treatment system used in the present work.

\section{Stage II: Assays With Addition of Coagulating Agents}

Stage II mainly involves the demonstration and discussion of the results obtained in the drainage bed system, dissolved air flotation (FAD), and filtration, with the addition of aluminum sulfate solution, as a coagulating agent. Indeed, in this stage, tests similar to those carried out in stage I were carried out, but in the presence of different concentration of aluminum sulfate solution $(5 \mathrm{mg} / \mathrm{L}, 10 \mathrm{mg} / \mathrm{L}$, and $15 \mathrm{mg} / \mathrm{L})$, used as a coagulant in the FAD unit. The tests carried out in this stage, intended to endeavor a better removal of solids, present both in suspension and in the dissolved state, with further corroboration by monitoring of the values of the physical parameters such as (a) apparent color, (b) true color, and (c) turbidity. Additionally, the variation in the $\mathrm{pH}$ 
Citation: Nilton Fernandes de Oliveira, et al., Evaluation of the quality of filter washing water and decanter sludge after sequential treatment by drainage bed, dissolved air flotation, and filtration. Australian Journal of Basic and Applied Sciences, 13(5): 35-42. DOI: 10.22587/ajbas.2019.13.5.4

values was also strived so as to keep it within the optimum range of use, thereby avoiding oscillations as it can hamper the performance of the water treatment system used in this stage.

Establishment of the flocculation $(\mathrm{Tm}=10 \mathrm{~min}, \mathrm{Gf}=25 \mathrm{~s}-1$, and $\mathrm{Vf}=35 \mathrm{RPM})$ and flotation values $\{(\mathrm{P}=400 \mathrm{~s}) \mathrm{KPa}$, Tsat $=$ $8 \mathrm{~min}$, and $\mathrm{R}=10 \%)$ ) were being done by performing flotation tests, followed by the subsequent filtration test on the three jars of the equipment. Further, the values regarding turbidity, apparent color, and true color meet the expectation, with the values being better than those obtained in the test carried out in stage I. Also, the $\mathrm{pH}$ values ranged from 6.8 to 7.9 , during all the tests carried out in this stage, thereby suggesting that $\mathrm{pH}$ values fall within the range (6.0 to 9.5), recommended by the Ministry of Health in the Ordinance No. 2,914/2011.

\section{CONCLUSIONS AND FINAL CONSIDERATIONS}

The present study was primarily focussed, on the evaluation of the feasibility of using a compact water treatment system, basically in the sanitation area, for the treatment of filters washing water and sludge from ETA decanters. For this purpose, the utilization of the Drainage Bed system was followed, by the subsequent application of the Dissolved Air Flotation, being identified to be efficient in the removal of particulate matter and filtration, both on a bench scale. To further validate this idea, the experiments were carried out in the absence and presence of the coagulant, in stage I and II, respectively. Additionally, three different dose level of the coagulant (aluminum sulfate), $5.0 \mathrm{mg} / \mathrm{L}, 10.0 \mathrm{mg} / \mathrm{L}$, and $15.0 \mathrm{mg} / \mathrm{L}$, was utilized in stage II. As per the expectation, the data collected demonstrated good treatment efficiency, even in the absence of the coagulant, which can be further explicated by the abundance of metals in this type of effluent (filter washing water + decanter sludge), in particular, aluminum in the present study. The presence of aluminum, in the effluent of the present case, favors the flocculation and thereby success of the subsequent steps. Although the turbidity and the color were removed, to a good extent in the absence of the coagulant, significant improvement in the results, obtained with the addition of the coagulant, was witnessed, which in turn produced high-quality water, as further corroborated by the monitored parameters. Therefore, one can deduce that this configuration turns out to be quite promising, and thus can be used as a good alternative of the recirculation of water in the system itself and certainly to the discharge of such effluents in water bodies. However, the application of the high-quality water, produced after the treatment, for drinking purpose necessitates the execution of further studies, mainly focusing on the sanitary safety of the produced water. Moreover, the use of different coagulants, a wider variation in the parameters involved in the processes, and finally, scaling up the experiment, has been suggested for carrying out the future studies.

Further, based on the studies carried out with the equipment designed and tested in the present study, the following conclusions were drawn:

Firstly, the evaluation of the physical, chemical, and biological parameters of the sludge mixture, (comprising of the decanter and washing water), obtained from the ETA filters, brings about the realization that the residues having values well-above the permissible level, according to the current legislation, cannot be discharged directly into the water bodies.

Secondly, the characterization of the physical drainage parameters, in the presence of three blankets (RT-21, RT-26, and RT-31), employed in the present work, enabled the assessment of the efficiency of drainage beds in retaining the apparent color. Additionally, in comparison to the values found in the crude sample of the sludge mixture, the utilization of the three blankets also facilitated the reduction in the retention of turbidity from $98 \%$ to $99 \%$.

\section{Stage I - Assays without addition of coagulating agent:}

The analysis carried out in stage I revealed that the turbidity values were above the maximum permitted values, as defined by Ordinance No. 2,914, of December 12, 2011. Admittedly, as a standard of portability, the turbidity values for rapid filtration is 0.5 UNT, and for slow filtration is 1.0 UNT. However, in the present case, the employment of drainage of the RT-21 blanket, at the outlets of the three filters, along with the utilization of drainage of the RT-26 blanket at the exits of Filters 01 and 02 , the turbidity values were found to be 5 UNT, which is within the maximum limit allowed along the distribution network of the water utility. Upon submitting the drainage of the RT-21 blanket to the Jar test, the reduction in the apparent color at the exit of the jar was found to be $69 \%$, whereas, in the outputs of the three filters, the reduction was noticed to be $90 \%$. On the other hand, the turbidity removal efficiency at the exit of the jar and at the exit of Filter 01, was observed to be 54\% and 96\%, respectively. These observations corroborate that even in the absence of the external coagulating agent in the FAD, the system was quite efficient in removing the apparent color, both at the exits of the jars as well as in the filter outputs. Therefore, one can deduce that among all the filters, Filter 01 exhibited the best performance, both with the drainage of the RT-21 blanket and with the drainage of the RT26 blanket.

Comparison of true color values in the samples of all the test carried out in stage I with the reference value, as established by the CONAMA Resolution 357/2005, established that these samples can be discharged directly in the water bodies.

Among all the three blankets, used in the present study, the drainage of the RT-31 blanket manifested the worst performance. The results indicated that turbidity changed from 132 UNT at bed exit to 87 UNT at the jugs outlets and 28 UNT at the exit of Filter 01. Thus, throughout the system, the reduction in turbidity was discovered to be only $79 \%$. Although the value establishes the worst performance in all the tests performed in the presence of the RT-31 blanket, a significant reduction of the solids present in the samples was discerned, which in turn indicates the efficiency of the RT-31 blanket in eliminating the solids from the samples.

\section{Stage II - Assays with the addition of coagulating agent:}

Stage II involves the addition of three different concentrations of aluminum sulfate solution $(5 \mathrm{mg} / \mathrm{L}, 10 \mathrm{mg} / \mathrm{L}, \mathrm{and} 15 \mathrm{mg} / \mathrm{L})$, used as a coagulating agent in FAD unit. The analysis led to the establishment of the appropriate coagulation conditions with the 
Citation: Nilton Fernandes de Oliveira, et al., Evaluation of the quality of filter washing water and decanter sludge after sequential treatment by drainage bed, dissolved air flotation, and filtration. Australian Journal of Basic and Applied Sciences, 13(5): 35-42. DOI: 10.22587/ajbas.2019.13.5.4

concentration of the coagulant being $15 \mathrm{mg} / \mathrm{L}$ and coagulation $\mathrm{pH}$ around 6.8 for the drainage of the RT-26 Filter 02 blanket. Further, the reduction in turbidity was $99.6 \%$ throughout the system. Similarly, the reduction in the apparent color in the jars and filter medium of Filter 02 was $96.4 \%$. Whereas the true color reduced from 29 UC at bed exits to 4 UC at the jugs outlets and Filter 02 , thereby establishing the reduction in true color to be just over $86 \%$. All the above parameters were found to be within the limits of portability of water defined by the Ministry of Health ordinance no. 2,914/2011.

The $\mathrm{pH}$, in both stage I and stage II, was within the range (6.0 to 9.5), recommended by the Ministry of Health in the Ordinance No. 2,914/2011 for the distribution system.

Further, the equipment of floteste (modified jar-test) was essential for carrying out the studies with the objective of removing the apparent color present in the collected samples, even without the application of external coagulating agent in the FAD.

In the process of removing turbidity via flotation followed by the filtration process, the turbidity removal efficiency of the filter using $0.42 \mathrm{~mm}$ grit sand was better than the filter using sand grains of $1.19 \mathrm{~mm}$.

Moreover, the study of the fast mixing conditions in the two stages (I and II) aided in choosing the appropriate time and velocity gradient used in the present work.

On the other hand, the air recirculation rate $(\mathrm{R}=10 \%)$ used in the present study, was efficient enough in removing the suspended and dissolved solids present in the drainage samples.

Therefore, the study performed in the two-step, developed in the present work, facilitated in demonstrating the performance and efficiency of the system composed of LD-FAD-Filtration.

However, there is an urgent need to carry out more studies on the subject, in the future, provided the political and environmental context of recent years, which in turn demands ETAs to bring into action various measures, thereby ensuring the maintenance and preservation of the environment, with the major focus on water resources.

\section{REFERENCES}

Achon, C. L.; Cordeiro, J. S. Management of ETA sludge - Free water removal through drying beds and ponds. Annals. Joinvile: 22nd.Congresso Brasileiro de Engenharia Sanitária e Ambiental, 2003.

Barroso, M. M. Influence of the micro and macroproperties of sludge from Water Treatment Plants in the dewatering by LD. 2007. 249f. Thesis (Doctorate) - Federal University of São Carlos (UFSCAR), São Carlos, 2007.

Brazilian Association Of Technical Standards. NBR 10.004: Solid waste - Classification. Rio de Janeiro, 2004.

Brazil. Law no. 9,433, of January 8, 1997. Lex: National Policy on Water Resources, 1997.

Brazil. Law No. 9,605, of February 12, 1998. Lex: Environmental Crimes, 2998.

Brazil. Law no. 12,305, of August 2, 2010. Lex: National Policy on Solid Waste, 2010.

Brazil. Ordinance of the Ministry of Health No. 2,914, of December 12, 2011. Lex: Minister of State of Health, in the use of the attributions granted by items I and II of the sole paragraph of art. 87 of the Federative Constitution of Brazil. It deals with the procedures for controlling and monitoring the quality of water for human consumption and its standard of potability.

Cordeiro J. S. The problem of sludge generated in decanters of water treatment plants. 2001. 342f. Thesis (doctorate) - School of Engineering of São Carlos (EESC / USP), São Carlos, 2001.

Evaluation of the aquifers of the city of Jacareí - SP, through the hydrogeological characterization of deep tubular wells. Annals. Campo Grande / MS: 23rd Brazilian Congress of Sanitary and Environmental Engineering, 2005.

Fontana, A. O. LD and Sedimentation System as a solution to reduce the volume of sludge from Decanters and Water Reuse of Filtration Washing - Case Study - ETA Cardoso. 2004. 164f. Dissertation (Master degree) - Federal University of São Carlos (UFSCAR), São Carlos, 2004.

Minas Gerais. Law no.13,199 of January 29, 1999. Lex: State Resources Policy

Hídricos, 1999.

Mott G. J., Romanow S. Sludge characterization, removal and dewatering. Journal of Harzardous Materials, n. 29, p. 127-140, 1992.

National Council For The Environment. Resolution no357, dated March 17, 2005. Provides for the classification of water bodies and environmental guidelines for their classification, as well as establishing the conditions and standards for effluent discharge, and other measures. Lex: Official Journal of the Union, n.053, p. 58-63, 2005.

Santos, Bruna. Evaluation of the application of the Drainage Bed system as a treatment of sludge from the Bom Jardim water treatment plant in Uberlândia-MG. Master Thesis, 2012. 